\section{Historia biográfica de la medicina chilena (1810-2010)}

\section{Lorenzo Cubillos y Ricardo Cruz-Coke}

Academia Chilena de Medicina/Instituto de Chile. Impreso en Chile por C y C Impresores Ltda. Santiago de Chile, 2014.

ISBN 978-956-8008-02-4

En 614 páginas, los autores y sus colaboradores presentan una visión analítica de la evolución de la medicina en Chile durante sus primeros dos siglos de historia republicana independiente, sintetizando los datos biográficos de 500 o más personas que han participado en actividades que guardan relación con este aspecto tan importante para el país. Con sólo estos datos se justifica catalogarla como una obra excepcional, la más extensa y detallada de que podemos disponer.

Los autores del libro son médicos que han dedicado muchos años al estudio de la historia de la medicina, no sólo recopilando datos sino también juzgando su relevancia en el ámbito nacional e internacional. En el prólogo, titulado "Presentación", dos autoridades de la Academia Chilena de Medicina destacan el propósito del libro, ajustado a su misión institucional: "el cultivo, la promoción $y$ difusión de la medicina, la educación médica y la salud pública". Conociendo a ambos prologuistas podemos comprender que su participación en este libro ha ido más allá que esta "Presentación". Así también, los autores han dejado constancia de los nombres de muchos colaboradores que fueron consultados al preparar sus diferentes capítulos, particularmente en sus introducciones temáticas. Agrega solidez al libro la investigación juiciosa y selectiva que hicieron los autores en diversas publicaciones, de autores doctos, sobre muchos aspectos de la historia de la medicina en Chile.

La "Medicina en la Historia", como la concibió Pierre Jacomet en su monumental obra con ese nombre, publicada con el patrocinio de Laboratorios Recalcine S.A. y en la cual tuve el honor de escribir el prólogo, debe estudiarse en un contexto que considera la geografía y clima en la época correspondiente, las características étnicas de sus pobladores, su organización política, social, religiosa, su arte y cultura en general, ajustándose a la premisa que "Una nación es un conjunto de personas con una historia, un presente y un sueño, una memoria y un proyecto". En el libro que nos brinda ahora la Academia Chilena de Medicina los autores se han esforzado por darnos una visión de los cambios que ha experimentado la medicina y en los cuales los médicos han sido actores fundamentales, pero no los únicos. Adecuadamente han destacado la influencia de sabios naturalistas, científicos en las áreas de la biología y ciencias experimentales, odontólogos, veterinarios. Particularmente en las primeras décadas analizadas destacan la participación de profesionales europeos que se avecindaron en Chile y jugaron roles fundamentales en la creación de instituciones, fundación de revistas científicas, formación de escuelas de medicina y en la guía del pensamiento de políticos y gobernantes, impulsando a una pléyade de profesionales chilenos que participaron en la evolución de la medicina nacional.

En diversos capítulos se analizan por separado las especialidades de la medicina existentes y consolidadas en el período que abarca este libro. En cada una se ofrece una síntesis biográfica de las personas más destacadas por su participación en actividades académicas universitarias, en sociedades médicas científicas, en salud pública nacional e internacional, en política y en organizaciones gremiales señeras, como el Colegio Médico de Chile. Sin duda algunos lectores van a lamentar la omisión de nombres que merecerían haber sido mencionados, pero ello es inevitable en toda obra de esta naturaleza y debería estimular a esos lectores para que soliciten la publicación de las biografías de las personas omitidas en las revistas de las respectivas sociedades científicas, incluyendo el propio Boletín de la Academia Chilena de Medicina. El recuerdo de nuestros maestros es una responsabilidad generacional que no debe eludirse.

No se necesita un don de oráculo para predecir que este libro será materia de consulta para la generación actual y las venideras que quieran aprender sobre cómo ha progresado la medicina en nuestro país y quienes han participado como gestores de este progreso.

Dr. Humberto Reyes Budelovsky Miembro de Número, Academia Chilena de Medicina. Profesor Emérito, Universidad de Chile. 